\title{
Reflexiones acerca de las desigualdades en América Latina
}

ENTREVISTA

\section{Por Ana Milena Passarelli}

Universidad Nacional de Quilmes, Universidad Nacional de La Plata, Argentina. ana.passarelli@unq.edu.ar

Recibido: abril del 2016

Aceptado: agosto del 2016

\section{Entrevista a}

Maristella Svampa es socióloga, escritora e investigadora del CONICET (Consejo Nacional de Investigaciones Científicas y Técnicas) en el Instituto de Investigaciones en Humanidades y Ciencias Sociales (IdIHCS) de la Universidad Nacional de La Plata. Es autora de múltiples libros que han abordado temas, entre otros, sobre los movimientos sociales, la función del Estado en América Latina, los modelos de desarrollo latinoamericanos. Entre sus obras más destacadas se encuentran "La sociedad excluyente" (2005); "15 mitos y realidades sobre la minería transnacional en Argentina" (2011); "Maldesarrollo. La Argentina del extractivismo y del despojo", co-escrito con Enrique Viale (2014) y, "El desarrollo en cuestión" (2015). Su último libro es "Debates Latinoamericanos. Indianismo, Desarrollo, Dependencia y Populismo" (2016). También es autora de tres obras de ficción, entre ellas, "El Muro" (2013).

Passarelli: Contanos ¿Cómo fue tu trayectoria?

Svampa: En realidad soy socióloga de casualidad. Estudié Filosofía en la Universidad Nacional de Córdoba, hice la licenciatura y a los 25 años me fui a Francia, a París. Hice dos maestrías, una en filosofía en la Sorbona para seguir más en la línea de filosofía política, historia de las ideas y otra, en historia bajo la dirección de Claude Lefort.

Cuando terminé mis maestrías, por suerte recibí una beca de una fundación francesa. Claude Lefort me dijo que él no podía dirigirme en la tesis de doctorado porque ya se jubilaba y que en ese caso podía acudir a otro director que era Daniel Pécaut, un especialista en estudios colombianos y por extensión latinoamericanista, que solamente dirigía en sociología y no en otras áreas. Con lo cual me encontré ante la alternativa de tener que hacer o dar un marco mucho más sociológico a mis trabajos, viniendo de una formación en filosofía e inclinada a la historia de las ideas. Fue una tesis de carácter teórico-bibliográfico, podríamos decir. Una investigación de carácter bibliográfico y que se instala en un cruce de caminos entre la historia de las ideas y la sociología política. Pero mucho más en la historia de las ideas con un fuerte componente sociopolítico porque lo que analiza son los avatares de la idea civilización o barbarie en el imaginario político argentino, lo cual es analizado no solamente a través de ciertos textos emblemáticos sino 
de la manera en cómo esta era proyectada en el campo político por periodistas y políticos de la época.

Cuando regresé al país en 1992, aunque me instalé de manera definitiva en 1994 en la Universidad de General Sarmiento (UNGS) y con una beca del CONICET, encaré la idea de empezar a hacer trabajo de campo para conectar de alguna manera esas lecturas que había hecho en el área de sociología.

Entonces en esa época, pleno menemismo, pleno auge del neoliberalismo no se me ocurrió una idea más original que estudiar sobre el peronismo. Original porque todos los sociólogos, si son argentinos, terminan por hacer un análisis del peronismo.

En la UNGS armamos un equipo de investigación muy interesante que durante siete $u$ ocho años participamos de varios proyectos de investigación. En ese marco realicé, por ejemplo, luego de mi incursión en la historia y los avatares del peronismo contemporáneo, mi segunda incursión fuerte en el libro "Desde abajo" -que no es un libro de investigación, un libro más propositivo- buscaba marcar agenda en la sociología contemporánea con el ingreso de los que en ese momento éramos jóvenes investigadores que planteábamos un enfoque diferente al de otras generaciones.

Mi segunda incursión fue con el equipo de la UNGS sobre el tema de countries y barrios privados, fue una investigación enorme que duró varios años. En octubre de 2001 publiqué el libro "Los que ganaron" y cierra mi período en UNGS una investigación sobre las organizaciones piqueteras que encaré en el año 2002. Fue una investigación que para mí dividió aguas, podríamos decir en mi trayectoria como profesional y como intelectual. A partir de esa investigación me autodefiní o busqué definirme como intelectual pública, interviniendo a través de notas de opinión, de expresar posicionamiento, también podríamos decir políticos.

Como corolario de esa etapa muy marcada por la investigación y la docencia en la UNGS está el libro "La sociedad excluyente", en el año 2005. Fue un libro, para mí de síntesis, en el cuál yo recurrí a mis investigaciones y por supuesto acudí a muchas otras para poder trazar una lectura general de lo que era la Argentina bajo el signo del neoliberalismo.

En 2007 decidí -de alguna manera- cerrar la etapa anterior y abordar una nueva temática que estaba más ligada a los nuevos conflictos socioambientales. A través del estudio de estos conflictos me acerqué nuevamente a ese mundo heterogéneo de las clases medias modernas movilizadas, que en este caso ilustraban un nuevo tipo de conflictividad. Es decir, los conflictos socioambientales son muy heterogéneos socialmente pero sin duda hay un marcado protagonismo de sectores de clase media. Entonces fue claramente un cambio de campo, no solo por el tipo de conflicto sino por el tipo de actores involucrados. También, en términos geográficos implicó un cambio fundamental, de ese devastado conurbano bonaerense en la época del neoliberalismo a los sacrificados territorios de las provincias argentinas en el marco del neodesarrollismo. Hay una brecha enorme que 
marca claramente este pasaje de tipo de conflictividad. A partir del año 2000 en Argentina y en América Latina en líneas generales hay una multiplicación de conflictos territoriales y socioambientales que marcan también el nivel de complejidad del mismo porque muchos de ellos se localizan en pequeñas y medianas localidades, quedan encapsulados en los territorios y asumen formatos específicos. También una narrativa diferente a la de otros movimientos sociales.

En el marco del neodesarrollismo populista o ese progresismo selectivo que caracterizó al Kirchnerismo tomé aquellos conflictos que eran los más invisibilizados, los que constituían un punto ciego para el progresismo; o en todo caso, había una posibilidad de mantenerlos en un segundo plano dado que estos se localizaban en pequeñas ciudades en los márgenes de los márgenes o afectaban a sectores campesinos indígenas en la zona de frontera, en la expansión de la frontera sojera, la frontera energética, la frontera florestal, la frontera minera. Sobre todas las cosas, la investigación en megaminería, en el año 2007, me abrió la posibilidad de reflexionar sobre temas de carácter global a nivel latinoamericano. Por un lado, la entrada por la vía de los dos conflictos socioterritoriales y ambientales me permitió pensar en clave regional puesto que lo que después denominaría extractivismo, consenso de los commodities, neodesarrollismo, encontraba un marco común en América Latina. En segundo lugar, me acercaba a debates más clásicos que habían atravesado la historia de América Latina, la historia del pensamiento y de la política; por ejemplo, el debate en torno al desarrollo.

En 2010, la opción de una reflexión más en clave latinoamericana se hizo posible, a su vez, por el hecho de que empiezo a integrar el denominado "Grupo de alternativas al desarrollo", un espacio compuesto por muchos intelectuales, críticos de la idea hegemónica de desarrollo.

Passarelli: ¿Cómo caracterizas el concepto de desigualdad social de manera general? ¿Cuáles crees que son las desigualdades que tienen mayor vigencia en América Latina?

Svampa: El concepto de desigualdad tiene una larga historia en las ciencias sociales. Es un concepto relacional que pone de relevancia, sobre todo, las relaciones de poder. Pensar en la desigualdad o en las desigualdades es pensar en las relaciones de poder, con lo cual es un concepto incómodo y además, políticamente disruptivo. No por casualidad, sobre todo en los años noventa, se hablaba más de pobreza -que es un concepto más estático- que de desigualdad -que implica a través de un análisis más dinámico hablar de sectores ricos y sectores pobres. América Latina es el continente más desigual pese a los cambios que ha habido porque efectivamente hablar de continente más desigual implica hablar, sobre todo, de la brecha existente entre los sectores más ricos y los sectores más pobres. 
Una primera cuestión a subrayar es que no se puede hablar de desigualdad en singular sino que hay que hablar de desigualdades, es decir, en plural, porque no podemos hablar solamente de la desigualdad de ingresos sino que para hacer una cartografía de las desigualdades en América Latina es necesario incorporar otras dimensiones como por ejemplo las desigualdades culturales, las desigualdades de género, las desigualdades étnicas, las desigualdades territoriales, las desigualdades socioambientales, por enumerar algunas. Sin establecer, además, una jerarquía o una primacía de unas sobre otras, hacer una cartografía es de índole muy complejo precisamente porque este es un concepto pluridimensional. El problema que tenemos es que en América Latina, y en Argentina en particular, hay una visión muy economicista que busca por sobre todas las cosas hacer una lectura en términos de brecha de ingresos. En ese sentido, me parece muy oportuno el libro de Gabriel Kessler "Controversias sobre la desigualdad" porque pone en agenda esta noción más pluridimensional de las desigualdades y hace un análisis meticuloso de estas distintas dimensiones.

En América Latina ha habido entre el año 2001 y 2012-2013 -cuando se cierra el súper ciclo de los commodities- una política general llevada a cabo tanto por gobiernos de índole progresistas como gobiernos más conservadores que implicaron una reducción fuerte de la pobreza.La pobreza descendió en América Latina porque efectivamente entramos a un nuevo ciclo económico basado en la exportación masiva de los commodities, lo que yo llamo el consenso de los commodities que involucró una rentabilidad extraordinaria y una ventaja comparativa para los países latinoamericanos que fortalecieron las áreas de exportación de sectores primarios, de productos primarios. Además, buscaron aprovechar precisamente esta oportunidad denegando o minimizando los nuevos procesos de resistencia y las nuevas desigualdades que se generaban como producto de este proceso. En América Latina, la reducción de la desigualdad por aumento de salarios, inclusión por el consumo y los planes sociales -que sobre todo se orientaron hacia los sectores más excluídos- tuvieron como base precisamente esa rentabilidad extraordinaria del sector extractivo. La mayor parte de los países latinoamericanos, ni siquiera aquellos con gobiernos progresistas de tinte más radical, tocaron a los sectores más poderosos para reducir las desigualdades. Un ejemplo claro es que no hubo reforma del sistema fiscal, del sistema tributario que es fundamental para reducir las desigualdades. No tocaron a los sectores más poderosos porque era más fácil extraer la rentabilidad extraordinaria a través de la exportación de commodities, de petróleo, de soja, de minerales o de gas que tocar a los sectores más poderosos, con lo cual al cierre del ciclo de los commodities el balance que hoy comienza a emerger es que efectivamente no hubo tal reducción de las desigualdades.

Más aún, los últimos estudios sostienen que en América Latina en realidad -ahora que los investigadores tenemos acceso a las declaraciones fiscales de los sectores más ricos- 
puede probarse que esa reducción de las desigualdades no fue tal. La participación de los sectores más ricos en los ingresos fue mucho mayor de la pensada. Con lo cual es necesario relativizar la hipótesis de que en los últimos 15 años hubo una reducción de las desigualdades. Las declaraciones fiscales de estos sectores, los sectores más ricos al menos dejan entrever un matiz muy importante.

La conclusión sobre estos procesos es que en los últimos 15 años en América Latina ha habido un proceso muy interesante, sin duda, desde el punto de vista político, pero uno podría decir que, en términos económicos sobre la cuestión de la desigualdad, los ricos se han hecho cada vez más ricos y los pobres apenas un poco menos pobres.

Passarelli: Es decir ¿La brecha existente se mantiene?

Svampa: La brecha se mantiene y, además, algunos de estos países al final del ciclo están siendo acosados por la inflación y por ende, por la pérdida del poder adquisitivo de los salarios. Con esto, esa diferencia que habían obtenido se va erosionando. Son ventajas muy volátiles las que se obtienen cuando solamente se fundamenta sólo en el salario.

Luego hay otras brechas que se abrieron, brechas de índole más territorial y socioambiental que son muy poco tenidas en cuenta a la hora de estudiar las desigualdades. Por ejemplo, si uno observa la cartografía de conflictos mineros y petroleros en América Latina, esa cartografía muestra que las poblaciones más castigadas por mega-proyectos de infraestructura son las poblaciones campesino-indígenas. Las desigualdades territoriales han afectado a los grupos más vulnerables -más allá de que incluyan también a otros sectores.

En términos de género, ha habido una brecha importante. Los estudios de la CEPAL (Comisión Económica para América Latina y el Caribe) indican que, en términos económicos, aumentó la pobreza femenina; más allá que hubo una reducción de la pobreza en general, existió un aumento de la pobreza femenina que sin duda responde también a cuestiones de índole muy compleja.

Una de las dimensiones sobre las cuales he indagado es la territorial y socio-ambiental, invisibilizada a lo largo de este proceso. Eso no quiere decir que no ha habido avances importantes. En el caso de la Argentina miremos lo que sucedió con todos los programas de inclusión y de reconocimiento de las llamadas minorías sexuales, es decir, tanto la ley de matrimonio igualitario como la ley de reconocimiento de otros géneros, son absolutamente innovadoras y han beneficiado a un sector de la sociedad que era absolutamente discriminado y que sufría procesos no sólo de discriminación sino de violencia social y simbólica muy importante. 
Passarelli: ¿Cuál es la relación existente entre la desigualdad y el extractivismo, en función de lo que denominas consenso de los commodities?

Svampa: Es un proceso de índole complejo y multidimensional porque al inicio uno podría decir que la expansión de megaproyectos genera diferentes desigualdades territoriales porque los territorios son sacrificados en función de un modelo de desarrollo extractivo y, porque en general las economías regionales son desplazadas, invisibilizadas y minimizadas. También se dan desigualdades sociosanitarias porque los impactos de estos modelos no son sólo territoriales sino que afectan al cuerpo, la salud de las personas: mujeres, niños, en el mediano y en el largo plazo. A su vez, podríamos leer en términos más políticos lo que sucede cuando nos encontramos ante mega proyectos que se imponen de manera vertical sobre los territorios sin tener en cuenta la voz de las poblaciones afectadas, en un marco en el cual efectivamente los impactos de estos modelos extractivistas es tan grande que sin duda debería involucrar la opinión, el sentir, el pensar de las poblaciones involucradas. En América Latina hay una ecuación que se afirma, que se consolida en este fin de ciclo que muestra que a más extractivismo hay menos democracia. Se avanza sobre los territorios sin el consentimiento de las poblaciones que están involucradas. En suma, todos estos mega proyectos que tienen fuertes impactos en los territorios generan nuevos procesos de desigualdades, un estallido de nuevas desigualdades que es necesario leer, insisto, en distintas dimensiones porque involucra inclusive a la política.

Un caso emblemático en Argentina es lo que sucede con el modelo sojero. Tocamos ahí no solo el núcleo económico, el núcleo de la economía Argentina en la actualidad sino que además estamos tocando una de las piezas claves del imaginario argentino. El modelo agrario fue naturalizado y fue leído como la normalidad, como la continuidad normal de otros modelos agrarios, sin percibir de manera explícita que había una fuerte ruptura entre el nuevo modelo agrario basado en paquetes tecnológicos de soja transgénica y glifosato, respecto del modelo anterior. Hoy en día el impacto sociosanitario que es percibido en las poblaciones, sobre todo poblaciones de escasos ingresos, las poblaciones más vulnerables que además tienen poco acceso al sistema de salud o si tienen acceso es un sistema deficitario, hoy, recién ahora, es decir, después de más 20 años de avance del modelo sojero, recién hoy podemos escuchar las voces de esos damnificados del modelo sojero.

Passarelli: En función de lo que desarrollas me parece interesante preguntar ¿Cómo se piensan estos modelos de desarrollo?, teniendo en cuenta que son procesos de poca duración y que tienen un alto impacto a nivel social. 
Svampa: Son procesos que tienen efectivamente una vida corta pero que, al mismo tiempo, lo que sucede es que inscriben grandes cambios en la estructura económica y social. Por ejemplo, los países latinoamericanos se han especializado en ciertos commodities. La Argentina se especializó en la soja y en algunos derivados. Entonces, lo que hemos visto en los últimos años es una tendencia a la reprimarización de las economías. Por otro lado, porque también en la búsqueda de socios comerciales América Latina dejó de lado el regionalismo autónomo y desafiante que había sido de alguna manera la gran consigna de los gobiernos progresistas al inicio, y abandonó este camino por la firma de convenios unilaterales con países como China, que tienen un rol cada vez mayor en la región y que van dando cuenta de una configuración neodependentista.

No es solamente que tienen un límite ligado al precio internacional de los commodities que han caído mucho a partir del año 2013 (sobre todo en minerales y petróleo, no tanto en el caso de la soj), sino que implican un proceso de reprimarización de las economías. Asimismo, la caída de los precios internacionales de las materias primas generan una vuelta de tuerca en el extractivismo, una suerte de efecto perverso que hace que en la medida que la rentabilidad es menor, los países latinoamericanos refuerzan aún más el extractivismo para poder -de alguna manera- obtener más beneficios económicos comparables a los de la vieja época. La caída del precio de los commodities lejos de abrir a la posibilidad de pensar otros modelos de desarrollo, lo que hace es reforzar la estructura extractivista y fomentar una expansión de las fronteras de explotación.

Sin embargo, hay que insistir que la crisis de los gobiernos progresistas no es sólo económica, no sólo tiene que ver con el fin del súper ciclo de los commodities y la crisis de la balanza comercial, sino con las insuficiencias del modelo de cambio y con cuestiones de índole política. Los gobiernos progresistas que inicialmente, insisto, concitaron muchas expectativas de democratización, pero finalmente fueron consolidando una narrativa populista clásica. Sabemos que el populismo es muy ambivalente, pues tienen elementos democráticos y no democráticos. Hoy se pone en evidencia el costado más oscuro del populismo, a través de la tendencia al hegemonismo y a la clausura, al cierre de las discusiones por la vía de la concentración del poder en manos de los líderes es una constante. Así, yo creo que el cierre del ciclo no es sólo económico, es político. Hay un cansancio de las sociedades hacia procesos que prometieron un cambio económico estructural y no lo lograron y, un proceso de concentración del poder político en mano de los líderes que aparecen como los mesías o los grandes salvadores. Es un momento muy difícil y que requiere además, una gran reflexión acerca de los límites del populismo, de cara al nuevo panorama que se abre en América Latina.

Passarelli: ¿Qué reflexión haces con respecto a este nuevo panorama latinoamericano? Svampa: Ahí soy muy pesimista pero antes de eso quisiera volver sobre el tema. 
Cuando uno hace el balance de los gobiernos progresistas, no tengo dudas de que hubo avances también en la democratización. Pero eso fue insuficiente y efectivamente lo que pasó en toda América Latina es que no se respondió a tres demandas fundamentales. Por un lado, no hubo un giro económico que implicaran transformaciones estructurales, para a partir de las cuales pudieran ser reconocidos como gobiernos de izquierda. Segundo, hubo una tendencia al cierre político institucional, lo que hizo que se identificaran cada vez con mayor claridad los elementos autoritarios de los gobiernos. Hay una tercera crítica sobre los modelos de desarrollo que es la que creo que está menos presente en la agenda pública; me refiero a la crítica eco-territorial que han hecho los movimientos sociales contra las diversas formas de extractivismo. Pero mientras para la izquierda clásica está mucho más presente el tema de que no ha habido un giro o un cambio en la matriz productiva y un cambio en la estructura social, para la derecha está mucho más presente el tema político institucional. Desde mi perspectiva deberían estar las tres críticas articuladas desde una posición de izquierda. Quiero decir, en América Latina la izquierda debería poder tomar estos tres problemas, estas tres dimensiones esenciales para pensar la política que se viene.

La política que se viene, sin duda, marca un giro hacia la derecha, un giro que además no sólo tiene que ver con las características nacionales de cada gobierno. Ahí quiero insistir también en la cuestión regional. En América Latina hubo una retórica regionalista muy importante en los últimos años que abrió efectivamente la posibilidad de pensar a la región como un espacio común, un momento muy rico. No por casualidad todos estamos pensando, los que miramos estos procesos, en clave latinoamericana.

En el año 2005, ocurrió la cumbre contra el ALCA (Área de Libre Comercio de las Américas) en Mar del Plata que tuvo un resultado positivo en la medida en que posibilitó el bloqueo del avance del tratado del libre comercio que proponía Estados Unidos. Esa cumbre para mí fue el logro articulado de una lucha que venían llevando a cabo las organizaciones sociales, los partidos políticos contestatarios y los líderes regionales. Es decir, fue una lucha articulada que mostró un gran protagonismo político, desde abajo y desde arriba.

Ese protagonismo regional desde abajo y desde arriba se va perdiendo, pese a que luego se crea la UNASUR (Unión de Naciones Suramericanas), la CELAC (Comunidad de Estados Latinoamericanos y Caribeños), el ALBA (Alianza Bolivariana para los Pueblos de Nuestra América) anteriormente, esa retórica regionalista desafiante se va perdiendo, va perdiendo esa doble dimensión y en definitiva se va estructurando como una retórica de los distintos gobiernos, una retórica desde arriba, es decir, una retórica que apela a los grandes protagonismos de los líderes; el UNASUR es una marca de eso. EI UNASUR debería haber sido el espacio del cual crear una plataforma regional para pensar a América Latina posicionándose, en el mundo y frente a los nuevos socios comerciales 
como China, como un actor pleno, autónomo. Sin embargo, terminó siendo la plataforma discursiva de los diferentes presidentes a través de largos discursos retóricamente ornamentados, en los cuales el protagonismo de las organizaciones sociales ha estado ausente.

En el medio surgió la Alianza del Pacífico y los gobiernos conservadores se fueron reorganizando y alineando nuevamente con Estados Unidos, se firmó el Tratado Transpacífico de Cooperación Económica (TPP). Primero lo firmó Perú y Chile. No sería extraño que Argentina, dado que Macri participa como observador de la Alianza del Pacífico quiera firmar el TPP que marca a las claras una orientación regional, un realineamiento con Estados Unidos en un rumbo muy conservador, distante de lo que se proponía originariamente el NO al ALCA.

En términos latinoamericanos, hay que observar que no sólo el giro a la derecha se acopla con esta reorientación hacia Estados Unidos. Los convenios firmados con China y esta asociación comercial implican también nuevas asimetrías, nuevas desigualdades. En suma, el panorama regional que se abre se instala en esta tensión entre Estados Unidos y China, si bien yo creo que puede haber una reorientación de los gobiernos en términos económicos, políticos e ideológicos hacia Estados Unidos.

Hay un giro hacia la derecha en América Latina que es necesario repensar entonces a la luz de lo que significaron los fracasos, las desmesuras, las promesas incumplidas de los progresismos, porque en definitiva la expectativa que había al inicio del ciclo en el año 2003-2005 tenía que ver con la idea de instaurar un nuevo campo de experimentación política en América Latina, con vistas a una transformación social radical, que en realidad no fue tal. 